\title{
Г.Х. Самигулов
}

\section{ИСПОЛЬЗОВАНИЕ ЭТНОНИМОВ В КАЧЕСТВЕ НАЗВАНИЙ ГРУПП ЯСАЧНОГО НАСЕЛЕНИЯ И СВЯЗАННЫЕ С ЭТИМ ПРОБЛЕМЫ ИЗУЧЕНИЯ ИСТОРИИ ЯСАЧНЫХ ВОЛОСТЕЙ: ЗАУРАЛЬЕ ХVII в.}

\author{
Исследование выполнено в рамках госзадания Минобрнауки РФ № 33.2644.2014к.
}

\begin{abstract}
Рассматривается использование этнонимов для обозначения ясачного населения: в Туринском и Тюменском уездах ясачных называли «татары», а в Уфимском уезде - «башкиры», в Верхотурском - «вогулы». Подобный подход позволяет объяснить ряд «темных» моментов в документах XVII в., в частности обозначение представителей одного рода различными этнонимами и «исчезновение» населения ряда ясачных волостей Верхотурского уезда.

Ключевые слова: Башкиры; вогулы; татары; ясачное население; ясачные волости; уезды.
\end{abstract}

Моя точка зрения относительно значения слов «башкиры», «вогулы» и «татары» в документах местного делопроизводства XVII в. была представлена в работе [1]. Слово «вогулы» в XVII в. выступало не только в качестве этнонима, но и в качестве обозначения ясачных людей Верхотурского уезда, вне зависимости от их этнической принадлежности. Обозначением ясачного населения в Туринском и Тюменском уездах было слово «татары», а в Уфимском уезде - «башкиры» [Там же]. Упомянутую публикацию можно считать вступлением к настоящей статье, в которой я несколько дополню изложенное ранее данными по другим (помимо Верхотурского) уездам, а также попытаюсь дать ответы на следующие вопросы: каким образом появлялись ясачные волости, состоящие из представителей одной родовой группы в разных уездах Урала и Зауралья; как обозначались в документах местных приказных изб представители одной и той же родо-племенной группы в разных уездах? И связанный с этим вопрос: как объяснить «исчезновение» в XVII в. населения некоторых ясачных волостей по Чусовой, в верхнем течении рек Уфа и Исеть из документов Верхотурского и Тобольского уездов? Мои изыскания местами будут иметь почти тезисный «характер», поскольку объем публикации не позволяет давать развернутые объяснения.

Уточним некоторые моменты, прежде чем перейти непосредственно к содержанию: 1.Ясачная волость подразумевала группу населения, платящего ясак. В отношении тюркского населения Урала и Сибири ясачные волости изначально формировались на основании улусов - владений родовой группы [2. С. 84-85]. 2. Поскольку практически все тюркское население Урала и Зауралья было скотоводческим, то улусы родоплеменных групп зачастую имели две части: зимнюю и летнюю, которые могли быть разнесены достаточно далеко. При формировании системы уездов система хозяйствования местного населения во внимание не принималась, и разные части одного улуса/волости могли оказаться в составе разных уездов. Так, одна часть улуса, терсяк, располагалась по р. Чусовой ниже p. Утка, по р. Ревда и до Аятского озера [3. С. 345-346; 4; 5. С. 30; 6. Л. 205-206]. Вторая часть территории этой же волости находилась на Исети: «вверх от Пышминской и Исетской волости, в районе впадения в Исеть речки Терсяк» [7. С. 47]. Сызгинская волость: северная ее часть располагалась в верхнем течении р. Уфа и по ее притокам - Саране, Сардаге, Юве [8. Л. 1; 9], в Верхотурском уезде, а вторая часть - на восточном склоне Уральского хребта к северо-востоку от оз. Аргази и р. Миасс [10], т.е. в Уфимском уезде. Таких волостей, разделенных между уездами, было больше, но для задач статьи приведенных примеров достаточно.

Туринский уезд был создан несколько позже Верхотурского, после основания г. Туринска (Епанчина) в 1600 г. Фактически ясачное население по Туре до этого времени платило подати в Тюмень, в 1600-1601 гг. произошло разделение этого населения между Верхотурским и Туринским уездами. Разделили сферы влияния по р. Тагил: жившие на Тагиле и вверх по Туре платили ясак в Верхотурье, жившие вниз по Туре от Тагила - в Туринск [11. С. 397].

Если еще в 1600-1601 гг. ясачное население по Туре называли и татарами, и остяками, и вогулами [11. С. 374, 378, 384-385, 397], то впоследствии происходит размежевание. 1645 г., октябрь, отписка царю верхотурского воеводы Стрешнева: «...прежде де сего у них ссоры и спору меж ими, Туринского и Верхотурского уездов у ясачных людей, о пашенных землях и о сенных покосех и о рыбных ловлях и о звериных промыслех и о всяких угодьях никакого не бывало, и ясачные де люди, Туринского острогу Татаровя и Верхотурского уезду Вогуличи, всякими промыслами промышляли, где кому сручно, меж собою смесицею» [12. С. 23]. Составлен этот документ был по поводу конфликта, возникшего при размежевании территорий Верхотурского и Туринского уездов - туринские ясачные тата- 
ры, «Енгильдейко Колмаков с товарищи», заявили, что подтверждать существующие межи не будут и потребовали включения в состав Туринского уезда земель по p. Нице по устью р. Реж, с Невьянской волостью, Ницынской, Ирбитской, Белослудской и Ощепковой слободами. Основная аргументация заключалась в том, что все это угодья туринских ясачных людей, а не Верхотурского уезда [12. С. 23]. Соответственно, когда верхотурский воевода писал о «Туринского острогу татаровях» и «Верхотурского острогу вогуличах», он имел в виду представителей одной и той же группы, разделенных границей уездов. Это подтверждается содержанием той фразы из документа, где сообщается, что раньше ясачные люди этих уездов хозяйствовали, где кому удобно, «меж собою смесицею».

В том, что раньше не было никаких споров о границах двух уездов, верхотурский воевода лукавил - в 1620 г. туринские ясачные татары разных юрт били челом туринскому воеводе Д. Милославскому на верхотурского жильца Артемия Бабинова, который поставил деревню на устье р. Реж. Территории по Нице и Реже ясачные татары описывали как свои охотничьи угодья, где «живут и лесуют звери: лоси и соболи, и лисицы, и в речках бобры...» [13. С. 296].

Приведенный пример показывает, что ясачное население Туринского уезда обозначалось словом «татары», в то время как родственное население в Верхотурском уезде называлось «вогулами». Этот вывод подтверждается наблюдением Б.О. Долгих: «Наши источники с 20-х годов XVII в. называют людей, плативших ясак в Туринский уезд, только татарами» [6. С. 34]. Ясачное население Тюменского уезда, так же, как и Туринского, обозначалось словом «татары» [13. С. 394-395; 14. Л. 169 и др.]

Как уже было сказано выше, ясачное население Уфимского уезда в XVII в. обозначалось словом «башкиры». Иначе говоря, в состав сословной группы ясачных башкир могли входить люди различной этнической принадлежности. Такая ситуация была показана на примере Верхотурского уезда [1], поэтому здесь ограничусь одним, но весьма характерным примером, который привел в одной из своих статей Б.А. Азнабаев: «...просьба Тогая Белякова от 1620 г. В своей челобитной он называет себя “казанским чувашенином Зюрейской дороги деревни Берсю”, однако указывает на то, что “...в Уфинском уезде в Юрминской волости вотчина моя от дедов и прадедов потому, что я, государь, башкирец и с той вотчины плачу ясак на Уфе с юрминскими башкирцами"» [15. С. 25]. При таком подходе, когда для обозначения ясачного населения в разных уездах использовались разные этнонимы, неизбежно возникали коллизии, когда представители одного рода, проживавшие в разных уездах, в документах (и не только в документах) носили разные «имена». Выше уже было показано, что ясачное население по р. Тура, представлявшее некую единую общность, оказалось разделено на «Туринского уезда татар» и «Верхотур- ского уезда вогуличей». Но в этом случае мы говорим о достаточно обобщенной группе Туринских ясачных людей, и не знаем даже - относились они к одной родовой группе (улусу) или к нескольким. Гораздо более выразительно это проявляется, когда речь идет о представителях одного рода, проживавших на территории разных уездов.

Наверное, наиболее ярким примером в этом отношении являлись терсяк. В Верхотурском уезде вплоть до последней трети XVII в. их называли вогулами [3. C. 346, 375-376; 16. С. 165-166]; в Тюменском уезде терсяк (как и все прочие ясачные) именовались ясачными татарами [13. С. 449, 455; 14. Л. 170]. В Уфимском уезде представителей рода терсяк обозначали как «башкир». Это можно выяснить при сопоставлении документов. В достаточно известных документах «Сыска и досмотра Ивана Полозова» перечислены некоторые башкирские селения Южного Зауралья, в том числе «от Катайского острогу по мере в 10-ти верстах живут башкирцы Россан-бек с товарыщи в 10-ти юртах, а от тех юрт в дву верстах у озера Коклану живут башкирцы Росланбек с товарыщи в 10-ти юртах <...> a от тех юрт в 5-ти верстах живут башкирцы Якшинбетко с товарыщи в 5-ти юртах...» [17. С. 85]. В 1768 г. терсяки Исетской провинции подали челобитную в Сибирскую губернскую канцелярию, где объясняли, что некоторые из башкир, перечисленных в сыске И. Полозова, - их родственники: «...из них, просителей, сотнику Чирикову Розсамбек дед, Ибрай Сабанов(у) Разсланбек дядя, Тапу Илгинееву Икшимбетко дед же родныя...» [18. Л. 92].

Иначе говоря, проживавшие в конце XVII в. на территории Уфимского уезда представители племени терсяк обозначались как башкиры. На оз. Маян и на p. Исеть обозначено расположение терсяков Уфимского уезда и в 1667 г. [17. С. 197-198]. Есть упоминания о Терсяцкой волости Уфимского уезда и в документах Верхотурской приказной избы, в частности в отписке воеводы верхотурского уфимскому коллеге по поводу жены, ушедшей от татарина в Уткинскую волость к отцу в «Уфинскую волости в Терсютцкие волости» от 7188 (1679-1680) г. [19. Стб. 228-228 об.] Судя по обращению к уфимскому воеводе, под словами «Уфинскую волости» подразумевался Уфимский уезд.

Ситуация обозначения ясачного населения разных уездов как «башкир», «вогулов» и «татар» существовала не только в XVII в. Фактически, претерпевая изменения, эта схема дожила до революции 1917 г. и отмены сословной системы в России. И эта система сыграла свою роль в формировании идентичности зауральских башкир и тюменско-туринских татар. Но вот о тюркоязычных вогулах после XVII в. практически не упоминается. Точнее, упоминания о «вогулах» ВерхУфимских, Терсякской или Чусовской волостей практически исчезают из документов к концу XVII в. В литературе имеются два варианта объяснения этого факта: 1) уход населения этих волостей за пределы уезда 
[20. С. 8-10]; 2) передача государством этих волостей из Верхотурского в Уфимский уезд [15. С. 75]. Представляется, что процесс носил совершенно другой характер. Тюрки никуда не уходили из волостей в верховьях Исети, по Чусовой или в верховьях Уфы - это были их вотчинные земли, и было бы очень странно оставить их еще до начала массированного давления русских переселенцев. Но как же произошло, что ясачное население этих волостей исчезло из документов Верхотурской приказной избы? Всё достаточно просто: это население просто сменило «приписку», т.е. люди стали писаться «башкирами» Уфимского уезда, но никакой передачи территорий не происходило. Верхотурская приказная изба просто не учитывала население, которое стало платить ясак в Уфу, поскольку эти люди не являлись податным населением Верхотурского уезда. Очень хорошо иллюстрирует этот процесс цитата из документа 1648 г.: «сказывал де им ясашной татарин Денметько Терсяк, а прежде сего он ясак плачивал на Тюмень, а ныне де он платит ясак на Уфу...» [13. С. 613]. В документе не говорится, что он переселился в Уфимский уезд, Денмет просто стал платить ясак не в Тюмень, а в Уфу. Как оказалось, такое происходило не только с отдельными людьми, но и с населением целых волостей.

Наиболее полно прослеживается подобная история на примере Сынрянской волости, которая располагалась в верхнем течении Исети и по ее притокам - Сысерти, Уктусу, Синаре. Первоначально Сынрянская волость входила в состав Тюменского уезда [21. С. 7]. Позже, с образованием Верхотурского уезда (1598), вошла в его состав, «сырянцы» Верхотурского уезда упоминаются еще в 1623 г. [13. С. 432]. К 1635 г. сынрян перешли в уфимский ясак. При этом они не сменили место жительства, и по-прежнему Сынрянская волость располагалась в верхнем течении Исети и по ее притокам Уктусу, Сысерти, Синаре. Но сынрян (сырянцы) считали, что живут «Уфимского уезда Сибирской дороги Сенирянской волости» [22. Л. 81 об.] Там же, в верховьях Исети, они жили и в 1663 г., когда у них укрывались тюменские ясачные татары Кинырской волости и терсяки с р. Реж из Верхотурского уезда [14. Л. 216]. В 1670 г. земли в верхнем течении р. Исеть перешли в ведение Тобольского уезда [23. Стб. 348 354; 24. Стб. 192-197], но на подведомственности сынрян это никак не сказалось, они по-прежнему платили ясак на Уфу. В 7205 (1697-1698) г. жители Сынрянской волости направили челобитную в Уфимскую приказную избу: «...да на их же вотчинников земли поселились русские многие люди четыре слободы Ремянская (Арамильская. - Г.С.), Камышенка, Колчедан, и Багаряк и в тех слободах населено дворов по триста и по четыре ста и болше...» [22. Л. 80].

Таким образом, сынрян жили на своих вотчинных землях, при этом территориально их угодья относились сначала к Тюменскому, с 1598 г. - к Верхотурскому, а с 1670 г. - к Тобольскому уезду, а сами они примерно с рубежа 1620-1630-х гг. платили ясак в Уфу. И называ- ли сынрян башкирами, или башкирскими татарами. Соответственно, ни для администрации Верхотурского уезда, ни, позже, для руководства Тобольского уезда их не существовало. Поэтому мы не видим сынрян в середине - второй половине XVII в. в документах ясачного сбора Верхотурской и Тобольской приказных изб.

По такой же схеме происходил «уход» ясачного населения Терсякской, Верх-Чусовской и ВерхУфимских волостей Верхотурского уезда. Терсякская волость действительно практически не упоминается в документах Верхотурской приказной избы с 1660-х гг. Та же ситуация и с тремя другими упомянутыми волостями. Но это вовсе не означает, что население куда-то ушло со своих земель. Приведу фрагмент описания границ Челжеутской (Салзаутской, Сальютской) волости из документа 1735 г.: «...до озера Болтой Чюсовское тож и около того озера по левую сторону чрез Урал камень на болшую дорогу что лежит из Екатеринбурха на Кунгур и по болшой дороге семь верст $<\ldots>$ на болшую дорогу лежащую из Екатеринбурга в Горной Щит к речке Сынарян Шитовской исток тож, от дороги немного вверх по левую сторону речки Сынарян, от речки Сынарян круто влево чрез луга на дорогу лежащую из Горного Щита в Арамилскую слободу, и по дороге чрез гору березником до лугов на правой руке от дороги верстах в двух близ речки Арамили виден камень Ракал называемые палатки тож...» [25. Л. 94-94 об.]. Но есть и описание границ этой же волости 1673 г., которое мало отличается от приведенного по локализации территории, но автор документа оперировал менее узнаваемыми названиями, хотя названия Чусовая и Арамиль (Аремыль) вполне понятны [26. Л. 139-140]. Фактически, территория Салзаутской волости Сибирской дороги Уфимского уезда включала в себя земли Верх-Чусовской и Чусовской ясачных волостей Верхотурского уезда.

Вовсе не из «пустоты» возникают в XVIII в. башкирские волости: Шигирская, Кущинская и Сызгинская в верхнем течении р. Уфа, Терсякская по Чусовой и Ревде [4, 9]. Терсякская сохранила свое название с XVII в., поскольку практически единственная из всех ясачных волостей Верхотурского уезда называлась по наименованию родового подразделения, составлявшего ее. А Сызгинская, Шигирская и Кущинская соотносятся с Верх-Уфимскими и, видимо, Бисертской волостью Верхотурского уезда. И еще один момент, который бы хотелось отметить: описанная схема перехода групп населения в ведомство соседнего уезда, не покидая своей территории, вовсе не означает, что не было случаев физического ухода отдельных людей и групп ясачного населения в другие уезды. Но и в этих случаях мы можем предположить переход в другую часть родового улуса, оказавшуюся после введения российской административной системы на территории другого уезда.

Сословное понятие «вогулы» в Верхотурском уезде размывалось не только благодаря процессам «ухода», 
как физического, так и административного, ясачного населения в ведение соседних уездов, но и в силу того, что слишком различные в культурном и хозяйственном отношениях группы населения с трудом поддавались осмыслению как нечто единое. Уже в последней трети XVII в. тюркское ясачное население Верхотурского уезда все реже обозначается в документах как «вогулы». Ясачные люди Уткинской, Бисертской волостей названы в документах татарами, причем как в челобитных, так и в воеводских отписках [19. Стб. 228-233; 27. Стб. 263-272]. Хотя еще встречается упоминание вогуличей Чусовской волости [28. Стб. 195]. В начале XVIII в. русские, платившие ясак, уже не фигурировали в документах как ясачные вогулы. Таким образом, в Верхотурском уезде использование этнонима «вогул» в качестве обозначения сословной группы ясачного населения постепенно сходило на нет, и к началу XVIII в. сословное значение термина «вогул», если и не совпадало с этническим, то стремилось к этому.

Сделаем краткие выводы: 1. В XVII в. существовала система обозначения ясачного населения в разных уездах Урала и Зауралья с помощью этнонимов.
В Верхотурском уезде ясачное население называлось «вогулы», вне зависимости от этнической принадлежности, в Уфимском - «башкиры», в Тюменском и Туринском уездах - «татары». 2. Эта система сохраняется и в последующее время, кроме Верхотурского уезда, где сословное понятие «вогулы» к началу XVIII в. «сжалось» и уже не включало в себя тюркское и славянское ясачное население. 3. В рамках этого подхода получает объяснение исчезновение из документов ясачного сбора Верхотурской приказной избы после 1660-х гг. населения Верх-Чусовской, Верх-Уфимских, Терсякской волостей и отсутствие в ясачных книгах Верхотурской, а позже Тобольской приказной избы населения Сынрянской волости. Вопреки существующим точкам зрения это население не покинуло свои родовые угодья, и эти волости не были официально переданы в ведение Уфимского уезда. Большая часть населения этих волостей перешла из верхотурского ясака в уфимский, не меняя территории проживания. При этом земли этих волостей по-прежнему оставались в составе Верхотурского и, частью, Тобольского уездов.

\section{ЛИТЕРАТУРА}

1. Самигулов Г.Х. «Этнонимы» как социальные термины: Зауралье XVII века // Тезисы XVII Международной Западносибирской археологоэтнографической конференции (20-22 апреля 2016 г., Томск, Россия). URL: http://zsaek.tsu.ru

2. Самигулов Г.X. К изучению исторической географии территорий по Исети и Пышме XVII века // Вестник Пермского университета. 2016. Серия: История. Вып. 1 (32). С. 84-95.

3. Миллер Г.Ф. История Сибири. М. : Вост. лит., 2005. Т. III. 598 с.: ил.

4. Государственный архив Свердловской области (далее-ГАСО). Ф. 59. Оп. 7. Д. 115.

5. Свистунов В.М., Меньшенин Н.М., Самигулов Г.Х. Первые демидовские заводы на Южном Урале. Челябинск, 2007. 224 с.

6. Объединенный государственный архив Челябинской области. Ф. И-172. Оп. 1. Д. 7.

7. Долгих Б.О. Родовой и племенной состав народов Сибири в XVII в. М., 1960. 623 с.

8. Государственный архив Пермского края (далее - ГАПК). Ф. 297. ОП. 2. Д. 88.

9. ГАСО. Ф. 59. Оп. 15. Д. 16.

10. ГАСО. Ф. 59. Оп. 3. Д. 2236.

11. Миллер Г.Ф. История Сибири. 3-е изд. М, 2005. Т. І. 630 с.: ил., карта.

12. Акты исторические, собранные и изданные Археографическою комиссиею. СПб., 1842. T. IV: $1645-1676.587$ с.

13. Миллер Г.Ф. История Сибири. М., 2000. Т. ІІ. 796 с., карта.

14. Санкт-Петербургский филиал Архива Российской академии наук. Ф. 21. Оп. 4. Д. 8.

15. Азнабаев Б.А. Интеграция Башкирии в административную структуру Российского государства: (вторая половина XVI - первая треть XVIII вв.) Уфа, 2005. 228 с.

16. Акты исторические, собранные и изданные Археографическою комиссиею. СПб., 1841. Т. III. 1613-1645. 501 с.

17. Материалы по истории Башкирской АССР. М. ; Л, 1936. Ч. І. 629 с.: ил.

18. ГАПК. Ф. 177. Оп. 2. Д. 121.

19. Российский государственный архив древних актов (далее - РГАДА). Ф. 1111. Оп. 1. Д. 240.

20. Байдин В.И., Грачев В.Ю., Коновалов Ю.В., Мосин А.Г. Уктус, Уктусский завод и его окрестности в XVII-XVIII вв. Екатеринбург : ООО «Грачёв и партнеры», 2011. 68 с.

21. Буцинский П.И. Заселение Сибири и быт ея первых насельников. Харьков, 1889. 353 с.

22. ГАСО. Ф. 24. ОП. 1. Д. $1092 \mathrm{a}$.

23. РГАДА. Ф. 111. Оп. 1. Д. 150.

24. РГАДА. Ф. 111 . ОП. 1. Д. 306.

25. ГАСО. Ф. 24 . Оп. 1. Д. 644.

26. ГАСО. Ф. 24. Оп. 1. Д. 385.

27. РГАДА. Ф. 1111 . ОП. 1. Д. 312.

28. РГАДА. Ф. 1111. Оп. 1. Д. 262.

Samigulov Gayas H. South Ural State University (Chelyabinsk, Russia). E-mail: Gayas_@mail.ru

USAGE OF ETHNIC GROUPS NAMES AS DESIGNATIONS OF THE YASAK POPULATIONS AND RELATED PROBLEMS OF THE STUDY OF THE YASAK VOLOST HISTORY: TRANS-URALS DURING XVIITH CENTURY AD.

Keywords: Bashkirs; Voguls; Tatars; yasak population; yasak volost; uyezd.

The article concerns the problem related to the source study as well as the social and ethnic history of the Urals and Siberia: what is a meaning of conceptions of the "Bashkir", "Vogul" and "Tatarin" in the XVII century documents? Source analysis demonstrates that the terms, on the one hand, were as a name for ethnic groups; on the other hand, they were used for the designation of the yasak population in the different uyezds. So, in Verkhoturye uyezd the yasak population was designated as "the Voguls", in Ufa uyezd - as "the Bashkirs", in Tura and Tyumen uyezds as "the Tatars". The yasak population was not ethnically homogeneous even in the same uyezd. It was 
especially clear in Verkhoturye uyezd where the Turks constituted substantial proportion of the yasak population but there were a small amount of the yasak Slavs and, certainly, the native Voguls (the Mansi people). All of them were designated as "the yasak Voguls" in the Verkhoturye uyezd documents. At the same time, the Turkic population of Verkhoturye uyezd maintained the close relations to the Turks from Ufa and Tyumen uyezds. The point is that the clan lands of some Turkic clans turned out to be divided between different uyezds. For example, a part of the Tersyak clan lands fell into Verkhoturye uyezd, a part - into Ufa uyezd and a part - in Tyumen one. Correspondingly, some of representatives of the Tersyak clan were named as "Voguls" in the documents, some - as "the Bashkirs" and some - as "the Tatars". This is only one example but it clearly demonstrated that we should not interpret the terms in the 17 century AD documents as the name of ethnic groups solely. The interpretation of ethnic (or, at least, the language one) affiliation of the specific groups of the yasak population is possible only be means of the complex analysis of the documents, including the later period. Some authors wrote that the yasak people of Synryanskaya, Tersyakskaya, Ayatskaya and Verkhne-Ufimskaya volosts of Verkhoturye uyezd left their territories in the different periods, and the lands remained unsettled. Due to the analysis of broader documental sources, it becomes quite clear that the population of these volosts did not leave anywhere; they simply started paying their yasak in Ufa instead Verkhoturye. They lived in the territory of the Verkhoturye uyezd but they were recorded as the yasak people of Ufa uyezd. In the other words, they stopped to be "the Voguls" and became "the Bashkirs" and information about them could be found in the Ufa uyezd documents. The comprehension that some of names of the ethnic groups were used in Russia as the terms for designation of the estate groups allows us to interpret more correctly some archive sources.

\section{REFERENCES}

1. Samigulov, G.Kh. (2016) ["Ethnonyms" as social terms: Trans-Urals in the 17th century]. Tezisy XVII Mezhdunarodnoy Zapadnosibirskoy arkheologo-etnograficheskoy konferentsii [Abstracts of the 17th International West Siberian Archaeological and Ethnographic Conference]. Tomsk. April 20-22, 2016. [Online] Available from: http://zsaek.tsu.ru/sites/default/files/webform/\%D0\%A1\%D0\%B0\%D0\%BC\%D0\%B8\%D0\% B3\%D1\%83\%D0\%BB\%D0\%BE\%D0\%B2 \%D1\%82\%D0\%B5\%D0\%B7\%D0\%B8\%D1\%81\%D1\%8B.pdf. (In Russian).

2. Samigulov, G.Kh. (2016) K izucheniyu istoricheskoy geografii territoriy po Iseti i Pyshme XVII veka [Studying the historical geography of the territories on the Iset and Pyshma in the 17th century]. Vestnik Permskogo universiteta-Perm University Herald. 1(32). pp. 84-95.

3. Miller, G.F. (2005) Istoriya Sibiri [History of Siberia]. Moscow: Vostochnaya literatura.

4. The State Archives of Sverdlovsk Region (GASO). Fund 59. List 7. File 115.

5. Svistunov, V.M., Menshenin, N.M. \& Samigulov, G.Kh. (2007) Pervye demidovskie zavody na Yuzhnom Urale [The first Demidov's plants in Southern Urals]. Chelyabinsk: RAS.

6. The Joint State Archives of Chelyabinsk Region (OGAChO). Fund I-172. List 1. File 7.

7. Dolgikh, B.O. (1960) Rodovoy i plemennoy sostav narodov Sibiri v XVII v. [The clan and tribal structure of the peoples in Siberia in the 17th century]. Moscow: USSR AS.

8. The State Archives of Perm Region (GAPK). Fund 297. List 2. File 88.

9. The State Archives of Sverdlovsk Region (GASO). Fund 59. List 15. File 16.

10. The State Archives of Sverdlovsk Region (GASO). Fund 59. List 3. File 2236.

11. Miller, G.F. (2005) Istoriya Sibiri [History of Siberia]. 3rd ed. Vol. 1. Moscow: RAS.

12. Russian Archeological Commission. (1842) Akty istoricheskie sobrannye i izdannye Arkheograficheskoy komissiey [Historical Acts collected and published by the Archeological Commission]. Vol. 4. St. Petersburg: [s.n.].

13. Miller, G.F. (2000) Istoriya Sibiri [History of Siberia]. Vol. 2. Moscow: RAS.

14. St. Petersburg Branch of the Archives of the Russian Academy of Sciences. Fund 21. List 4. File 8.

15. Aznabaev, B.A. (2005) Integratsiya Bashkirii v administrativnuyu strukturu Rossiyskogo gosudarstva: (vtoraya polovina XVI - pervaya tret' XVIII $v v$.) [Integration of Bashkortostan in the administrative structure of the Russian state (the late 16th - early 18th centuries)]. Ufa: [s.n.].

16. Russian Archeological Commission. (1841) Akty istoricheskie, sobrannye i izdannye arkheograficheskoyu komissieyu [Historical Acts collected and published by the Archeological Commission]. Vol. 3. St. Petersburg: [s.n.].

17. USSR Institute of History. (1936) Materialy po istorii Bashkirskoy ASSR [Materials on the history of the Bashkir Autonomous Soviet Socialist Republic]. Moscow; Leningrad: RAS.

18. The State Archives of Perm Region (GAPK). Fund 177. List 2. File 121.

19. The Russian State Archive of Ancient Documents (RGADA). Fund 1111. List 1. File 240.

20. Baydin, V.I., Grachev, V.Yu., Konovalov, Yu.V.\& Mosin, A.G. (2011) Uktus, Uktusskiy zavod i ego okrestnosti v XVII-XVIII vv. [Uktus, Uktussky plant and its surroundings in the 17th -18 th centuries]. Ekaterinburg: Grachev i partnery.

21. Butsinskiy, P.I. (1889) Zaselenie Sibiri i byt eya pervykh nasel'nikov [The population of Siberia and the life of its first settlers]. Kharkov: Tip. Gubernskago pravleniya.

22. The State Archives of Sverdlovsk Region (GASO). Fund 24. List 1. File 1092a.

23. The Russian State Archive of Ancient Documents (RGADA). Fund 111. List 1. File 150.

24. The Russian State Archive of Ancient Documents (RGADA). Fund 111. List 1. File 306.

25. The State Archives of Sverdlovsk Region (GASO). Fund 24. List 1. File 644.

26. The State Archives of Sverdlovsk Region (GASO). F. 24. List 1. File385.

27. The Russian State Archive of Ancient Documents (RGADA). Fund 1111. List 1. File 312.

28. The Russian State Archive of Ancient Documents (RGADA). Fund1111. List 1. File 262. 